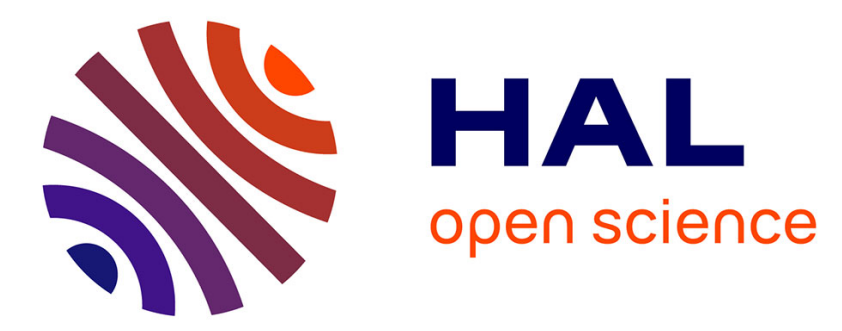

\title{
Cognitive Characteristics of Strategic and Non-strategic Gamblers
}

Aurélie Mouneyrac, Céline Lemercier, Valérie Le Floch, Gaëlle Challet-Bouju, Axelle Moreau, Christian Jacques, Isabelle Giroux

\section{- To cite this version:}

Aurélie Mouneyrac, Céline Lemercier, Valérie Le Floch, Gaëlle Challet-Bouju, Axelle Moreau, et al.. Cognitive Characteristics of Strategic and Non-strategic Gamblers. Journal of Gambling Studies, 2018, 34 (1), pp.199-208. 10.1007/s10899-017-9710-6 . hal-01570890

\section{HAL Id: hal-01570890 \\ https://hal.science/hal-01570890}

Submitted on 1 Aug 2017

HAL is a multi-disciplinary open access archive for the deposit and dissemination of scientific research documents, whether they are published or not. The documents may come from teaching and research institutions in France or abroad, or from public or private research centers.
L'archive ouverte pluridisciplinaire HAL, est destinée au dépôt et à la diffusion de documents scientifiques de niveau recherche, publiés ou non, émanant des établissements d'enseignement et de recherche français ou étrangers, des laboratoires publics ou privés. 


\section{Cognitive Characteristics of Strategic and Non-Strategic Gamblers}

Aurélie Mouneyrac ${ }^{1}$, Céline Lemercier ${ }^{1}$, Valérie Le Floch ${ }^{1}$, Gaëlle Challet-Bouju ${ }^{2,3}$, Axelle Moreau $^{4}$, Christian Jacques ${ }^{5}$ \& Isabelle Giroux ${ }^{5}$

${ }^{1}$ CLLE, Université de Toulouse, CNRS, UT2J, France

${ }^{2} \mathrm{CHU}$ Nantes, Addictology \& Psychiatry Department, Federative Institute of Behavioral Addictions, France

${ }^{3}$ University of Nantes, University of Tours, UMR INSERM 1246 SHERE, Nantes, France ${ }^{4}$ Laboratoire OCTOGONE, Université de Toulouse, France

${ }^{5}$ Université Laval, Québec, Canada

aurelie.mouneyrac@univ-tlse2.fr

Address correspondence to: A. Mouneyrac, University of Toulouse; 5, allées Antonio

Machado; 31058 Toulouse Cedex 9 - France; aurelie.mouneyrac@ univ-tlse2.fr;

$+33561503681$

To cite this article:

Mouneyrac, A., Lemercier, C., Le Floch, V., Challet-Bouju, G., Moreau, A., Jacques, C., \& Giroux, I. (2017). Cognitive characteristics of strategic and non-strategic gamblers. Journal of Gambling Studies. https://doi.org/10.1007/s10899-017-9710-6

The final publication is available at Springer via http://dx.doi.org/10.1007/s10899-017-9710-6 
Running head: COGNITIVE CHARACTERISTICS

\begin{abstract}
Participation in strategic and non-strategic games is mostly explained in the literature by gender: men gamble on strategic games, while women gamble on non-strategic games. However, little is known about the underlying cognitive factors that could also distinguish strategic and non-strategic gamblers. We suggest that cognitive style and need for cognition also explain participation in gambling subtypes. From a dualprocess perspective, cognitive style is the tendency to reject or accept the fast, automatic answer that comes immediately in response to a problem. Individuals that preferentially reject the automatic response use an analytic style, which suggest processing information in a slow way, with deep treatment. The intuitive style supposes a reliance on fast, automatic answers. The need for cognition provides a motivation to engage in effortful activities. One hundred and forty-nine gamblers (53 strategic and 96 non-strategic) answered the Cognitive Reflection Test, Need For Cognition Scale, and socio-demographic questions. A logistic regression was conducted to evaluate the influence of gender, cognitive style and need for cognition on participation in strategic and non-strategic games. Our results show that a model with both gender and cognitive variables is more accurate than a model with gender alone. Analytic (vs. intuitive) style, high (vs. low) need for cognition and being male (vs. female) are characteristics of strategic gamblers (vs. non-strategic gamblers). This study highlights the importance of considering the cognitive characteristics of strategic and non-strategic gamblers in order to develop preventive campaigns and treatments that fit the best profiles for gamblers.
\end{abstract}

Keywords: gambling subtypes, cognitive style, need for cognition, gender, types of games 
Running head: COGNITIVE CHARACTERISTICS

\section{Cognitive Characteristics of Strategic and Non-Strategic Gamblers}

Identifying processes associated with gambling enables prevention experts and practitioners to set up informed actions. In recent years, the scientific community has attempted to provide a more precise definition than the general term of "gambling". This approach considers two gambling subtypes: strategic and non-strategic games (Bjerg, 2010; Boutin, 2010). In strategic games, the outcome is considered to be influenced both by chance and the skill of the gambler (e.g. poker, sports betting, horse-race betting, blackjack), while only chance is involved in non-strategic games (e.g. scratch cards, lotteries, slot machines, bingo, roulette). It turns out that the study of the processes involved in participation in strategic (or non-strategic) games rather than the alternative is of main importance for an understanding of participation in gambling.

Research has shown that strategic and non-strategic games appeal to different gamblers' profiles (Bjerg, 2010; Bonnaire, Bungener, \& Varescon, 2013; Boutin, 2010; Dickerson, 1993; Grant, Odlaug, Chamberlain, \& Schreiber, 2012; Moragas et al., 2015; Odlaug, Marsh, Kim, \& Grant, 2011; Stevens \& Young, 2010; Young \& Stevens, 2009). Some studies evaluated sociodemographic profiles of each subtype of gamblers. They have shown that gender is deeply involved in participation in strategic and non-strategic games. Men are more likely to gamble on strategic games and women are more likely to gamble on non-strategic games (LaPlante, Nelson, LaBrie, \& Shaffer, 2006; Moragas et al., 2015; Odlaug et al., 2011; Petry, 2003; Stevens \& Young, 2010; Young \& Stevens, 2009). It is supposed that men gamble for the thrill of gambling while women gamble to escape from reality (LaPlante et al., 2006).

However, the literature did not explain how gender plays a role in participation in strategic and non-strategic games. LaPlante et al. (2006) suggested that gender can be a direct factor or rather a proxy for processes commonly associated with gender. Especially, cognitive 


\section{Running head: COGNITIVE CHARACTERISTICS}

style and need for cognition could be involved in gamblers' participation in strategic and nonstrategic games (Grant et al., 2012; Lorains, Dowling, et al., 2014; Lorains, Stout, Bradshaw, Dowling, \& Enticott, 2014).

According to the classic dual-process view, cognitive style refers to the way individuals process information and make decisions (Evans \& Stanovich, 2013; Kahneman, 2011). Cognitive style is based on the assumption that humans process information in two ways, either intuitively, automatically and rapidly, or analytically, controlled and slowly (Evans \& Stanovich, 2013; Kahneman, 2011; Wiers \& Stacy, 2006). Intuitive reasoning is useful for tasks that require fast decisions, which necessitate few attentional resources and do not require working memory. Analytic reasoning is more conscious and thoughtful than intuitive reasoning. Indeed, analytic decisions require recruiting working memory and attentional resources. When individuals use analytic reasoning, they cannot handle simultaneous tasks. Finally, analytic reasoning also requires more time than intuitive reasoning. These two types of reasoning co-exist, but individuals rely preferentially on one or the other (De Neys \& Bonnefon, 2013; Frederick, 2005).

According to several studies, one main characteristic associated with cognitive style is gender (e.g. Brañas-Garza, Kujal, \& Lenkei, 2015; Cueva et al., 2016; Frederick, 2005; Hoppe \& Kusterer, 2011). Men are generally more analytical than women. This characteristic is shared both in cognitive style and gambling subtypes. This suggests that strategic gamblers might also be more analytic than non-strategic gamblers. In this perspective, we can suppose that analytic and intuitive individuals engage in strategic and non-strategic games because they meet those individual's specific needs.

Need for cognition is "the tendency for an individual to engage in and enjoy thinking" (Cacioppo \& Petty, 1982, p. 116). This concept refers to the extent to which individuals do or do not prefer to engage in effortful, onerous cognitive tasks. Need for cognition is correlated 


\section{Running head: COGNITIVE CHARACTERISTICS}

with cognitive style (Frederick, 2005; Toplak, West, \& Stanovich, 2014): the more individuals have a high need for cognition, the more they use the analytic cognitive style, and conversely. The literature thus suggests that cognitive style and need for cognition direct the activities individuals choose to practice (Frederick, 2005). Analytic style and high need for cognition would direct individuals toward time-consuming and onerous thinking tasks, while intuitive style and low need for cognition would direct individuals toward tasks that require faster analysis and less onerous thinking.

In gambling, it has been shown that poker and sports betting games attract players who gamble for intellectual stimulation (Binde, 2013). At the same time, horse-race gamblers are motivated by the search for knowledge and self-accomplishment (Chantal \& Vallerand, 1996). Conversely, games usually considered as non-strategic (e.g. lotteries, scratch cards, bingo) (Bjerg, 2010; Boutin, 2010) are identified as requiring little concentration and no skill. Bingo players gamble to relax (Binde, 2013), and lottery gamblers are motivated by money (Chantal \& Vallerand, 1996). These examples support the hypothesis that need for cognition and cognitive style are of main importance in the choice between strategic and non-strategic games.

The present study is the first to our knowledge to examine the influence of cognitive variables on strategic and non-strategic gamblers. Our assumption was that cognitive style and need for cognition could influence the participation in subtypes of games, independently from the influence of gender. More precisely, we hypothesized that strategic gamblers (vs. nonstrategic gamblers) would be analytical thinkers (vs. intuitive thinkers) and would exhibit a high (vs. low) need for cognition. 
Running head: COGNITIVE CHARACTERISTICS

\section{Method}

\section{Participants}

Participants were recruited through the Internet (social networks and on the distance learning platform of the Psychology Department of the University of Toulouse), and from the database of research volunteers constituted by the Federal Institute of Behavioral Addictions (Nantes, France).

Data collection was conducted between October 2014 and July 2016 based on an anonymous Internet survey (Qualtrics $\left.{ }^{\circledR}\right)$. Of the 312 respondents, 65 were considered as noneligible (non-gamblers) and 13 as incomplete (their answers about their gambling activity was not sufficiently precise to classify them as strategic or non-strategic gamblers). We classified gamblers according to the games they play. Individuals who spent their money on poker, sports betting, horse-race betting and blackjack were labelled strategic gamblers $(n=53)$ (Bjerg, 2010; Boutin, 2010). Gamblers of scratch cards, lotteries, slot machines, bingo and roulette were labelled non-strategic gamblers $(n=96)$. Individuals who gambled both on strategic and non-strategic games were considered as multi-games players. We excluded multi-games players from the analysis $(n=85)$.

Finally, the analysis included 149 subjects. The majority of participants were women (69.8\%). Almost half of the sample was composed of undergraduate students (51.7\%). Average age was $29.34(S D=.96)$. Ninety-four participants of this sample gambled on only one game, 54 gambled on two or three different games and one gambled on four different games. Tables 1 and 2 show the number of individuals in strategic and non-strategic games and in each game, plus their median frequency and the amount of money wagered by session. 
Running head: COGNITIVE CHARACTERISTICS

Table 1

Games Played, Median of Frequency and Amount of Money Wagered by Strategic Gamblers $(n=53)$

\begin{tabular}{lrlc} 
Games Played & \multicolumn{1}{c}{$n$} & Frequency of Gambling & Wagered per Session \\
\hline Poker & 45 Once per week & $€ 5-20$ \\
Sports Betting & 17 Once per week & $€ 5-20$ \\
Horse-Race Betting & 1 & More than once a day & $€ 101-200$ \\
Blackjack & 1 & A few times a year
\end{tabular}

Note. Reading key: among the 53 strategic gamblers, 45 gambled at least on poker. Median frequency of poker gambling was once a week and participants' median amount of money spent per session was five to 20 euros.

Table 2

Games Played, Frequency and Amount of Money Wagered by Non-Strategic Gamblers $(n=$ 96)

\begin{tabular}{lrlc} 
Game Played & $n$ & Frequency of Gambling & Wagered per Session \\
\hline Scratch Cards & 58 & A few times a year & $<€ 5$ \\
Lotteries & 55 & Less than monthly & $<€ 5$ \\
Slot Machines & 19 & A few times a year & $€ 5-20$ \\
Bingo & 15 & A few times a year & $€ 5-20$ \\
Roulette & 7 & A few times a year & $€ 21-50$ \\
\hline
\end{tabular}

Note. Reading key: among the 96 non-strategic gamblers, 58 gambled at least on scratch cards. Median frequency of scratch card gambling was a few times a year and participants' median amount of money spent per session was less than five euros.

\section{Measures}

Gambling activity: Participants were asked about participation in gambling games using a multiple choice question. Answer choices were a list of the most frequent games (e.g. poker, slot machines, lottery, etc.), with the possibility of entering unlisted games and one choice for non-gamblers. Each answer (except for non-gamblers) redirected participants to questions asking their frequency of gambling (nine choices from "less than once a year" to "more than 


\section{Running head: COGNITIVE CHARACTERISTICS}

once a day") and the mean sum they bet each time they gambled (nine choices from "zero" to "more than 500 euros") on each game selected.

Cognitive style: The Cognitive Reflection Test (CRT; Frederick, 2005) consists of three problems to solve. For each of these problems, one typical answer springs quickly to mind but is wrong. A second answer comes with a delay, which is correct. One example of the CRT is the problem below: If it takes 5 machines 5 minutes to make 5 widgets, how long would it take 100 machines to make 100 widgets? minutes. In this problem, the typical fast but wrong answer (intuitive answer) is 100 minutes. However, each machine operates simultaneously, thus the number of machines or widgets does not change the time each machine needs to produce one widget. The correct answer (analytic answer) is 5 minutes. The more correct answers individuals produce, the more they are considered as analytic. Possible scores varied from 0 to 3. Instructions used for this experiment were We will now present you with some problems to solve, instead of the instructions used by Frederick (2005) (Below are several problems that vary in difficulty. Try to answer as many as you can). After completing the CRT, we added a question which was Have you already answered these problems before? Fifty-two participants answered yes and were excluded from the analysis. Repeated testing is an issue for CRT because it makes little sense to re-test for problems where the answers are already known by the participant (Haigh, 2016; Stieger \& Reips, 2016).

Need for cognition: The French version of the Need For Cognition Scale (NFCS) (Cacioppo, Petty, \& Kao, 1984; validated by Salama-Younes, Guingouain, Le Floch and Somat (2014)) uses an 11-item questionnaire to evaluate the tendency to engage in a reflective task. Each item is evaluated on a four-point Likert scale from completely false to completely true. The higher individuals score on this scale, the more they are considered as needing cognition (scale from 0 to 44$)$. Internal consistency for this scale was good $(\alpha=.83)$. 
Running head: COGNITIVE CHARACTERISTICS

\section{Procedure}

The experiment was run online. Free consent and sociodemographic information were collected first. The experiment began with the CRT, followed by the gambling activity questions, and ended with the NFCS.

\section{Analysis}

IBM SPSS Statistics 20 was used for the analysis. We used multiple logistic regression to determine the influence of gender, cognitive style and need for cognition on participation on strategic and non-strategic games.

\section{Results}

\section{Logistic regression}

A step by step descending logistic regression was run to predict participation in strategic and non-strategic games based on gender, cognitive style and need for cognition. The model with the three predictors was statistically significant $\left(\chi^{2}(3)=43.88, p<.001\right)$.

Nagelkerke's $\mathrm{R}^{2}$ of .35 indicated a moderate relationship between prediction and grouping. This model was able to classify $77.2 \%$ of the observations correctly. The three predictors were significant (see Table 3) and each of them contributed to the fit of the model with the data ( $p$ values of log likelihood for the three predictors are less than .005). Men were more likely to gamble on strategic games, the odds ratio being $4.61(B=1.53, p=.001,95 \% C I$ [2.01-10.56]). Furthermore, analytic cognitive style increased 1.81 times the likelihood of gambling on strategic games rather than non-strategic games $(B=.596, p=.004 ; 95 \% C I$ [1.21-2.72]). Need for cognition increases 1.10 times the likelihood of gambling on strategic games rather than non-strategic games $(B=.099, p<.007 ; 95 \% C I[1.03-1.19])$. Table 3 shows descriptive results of strategic $(n=53)$ and non-strategic gamblers $(n=96)$ by gender, cognitive style and need for cognition. 
Running head: COGNITIVE CHARACTERISTICS

Table 3

Gender, Cognitive Style and Need for Cognition of Strategic and Non-Strategic Gamblers

\begin{tabular}{|c|c|c|c|c|}
\hline & Strategic & Non-Strategic & Multivariate \\
\hline & & $n$ or $M(S D)$ & $n$ or $M(S D)$ & OR $[95 \% C I]$ \\
\hline \multirow{2}{*}{ Gender } & Men & 30 & 16 & \multirow{2}{*}{$4.90[2.15-11.14]^{* *}$} \\
\hline & Women & 24 & 80 & \\
\hline \multicolumn{2}{|c|}{ Cognitive Style ${ }^{a}$} & $1.76(1.06)$ & $.85(.94)$ & $1.76[1.18-2.62]^{* *}$ \\
\hline \multicolumn{2}{|c|}{ Need for Cognition ${ }^{b}$} & $32.61(4.52)$ & $28.83(6.33)$ & $1.11[1.03-1.19]^{* *}$ \\
\hline
\end{tabular}

Note. ${ }^{a}$ Cognitive style (CRT): on a scale from 0 to 3 , and higher score indicated more analytic style. ${ }^{b}$ Need for Cognition (NFCS): on a scale from 0 to 44 and higher score indicated more needing cognition.

$* * p<.01$

\section{Discussion}

The main goal of this study was to investigate the influence of cognitive style and need for cognition on participation in strategic and non-strategic games. The results of our study support this hypothesis. Our study shows the existence of a model that can explain participation in strategic and non-strategic games. This shows that games are not randomly chosen by gamblers. The model includes cognitive and demographic variables (gender, cognitive style and need for cognition). As expected, gender is the main predictor of the model, our results indicating that men are more than four times more likely to gamble on strategic games than women.

However, cognitive style and need for cognition increase the precision of the model. As suggested in the literature, gender may not have the same effect when combined with other variables to explain participation in strategic and non-strategic games (Petry, 2003). Cognitive variables are thus relevant for constructing the profiles of strategic and non-strategic gamblers. Other explanatory variables might also have contributed to this model and led to a better understanding of the differences between the two types of gamblers. More research is needed to develop a model that adequately describes these populations. 
Running head: COGNITIVE CHARACTERISTICS

Cognitive style and need for cognition were both significant predictors in the model. Our results show that analytic cognitive style multiplies the probability of participating in strategic rather than non-strategic games by 1.8. This result highlights the fact that individuals who participate in strategic games have different cognitive characteristics from those participating in non-strategic games. The last predictive variable of our model is need for cognition. The more gamblers like to engage in effortful cognitive activities, the more they are likely to be strategic gamblers rather than non-strategic gamblers. This suggests that strategic and non-strategic games meet multiple personal needs, with strategic games meeting a need for cognition, for example. The existence of the influence of individual needs on participation in strategic and non-strategic games seems to confirm the idea that gamblers are attracted by specific features of the subtypes of games.

Our results thus indicate that cognitive variables can explain participation in strategic and non-strategic games. Individuals can be divided into two types according to their cognitive preferences. First, non-strategic gamblers might process information in a fast, automatic way and be more inclined to trust their intuition. Second, strategic gamblers might use a slower and more controlled way of processing information than non-strategic gamblers. Considering this variable seems to be of main importance for any further exploration of gamblers' profiles. The literature has already demonstrated that socio-demographic, neurological and personality traits and clinical variables explain participation in strategic and non-strategic games (Bonnaire et al., 2013; Dickerson, 1993; Grant et al., 2012; Moragas et al., 2015; Odlaug et al., 2011; Stevens \& Young, 2010; Young \& Stevens, 2009). A global model that takes into consideration these variables plus cognitive variables might make it possible to draw a better picture of gamblers' subtypes.

The above studies suggest that gamblers can be considered as a heterogeneous population. Gamblers can be from at least one of two types of individuals (strategic and non- 


\section{Running head: COGNITIVE CHARACTERISTICS}

strategic) with specific characteristics. In this context, it is of main importance to consider their specificities in the elaboration of prevention campaigns and of treatments for excessive gambling. Indeed, research in cognitive and social psychology has shown that cognitive style and need for cognition moderate the efficacy of persuasive campaigns (Priester \& Petty, 1995; Shi, 2013; Steward, Schneider, Pizarro, \& Salovey, 2003). More studies are thus needed to better characterize populations of gamblers. They will help adjust and improve means and methods for preventing and treating excessive gambling behavior.

\section{Limits of the study}

The first limit of the study is linked to the population (Moreau, Chabrol, \& Chauchard, 2016). The online recruitment of gamblers made it difficult to reach individuals who gamble regularly on games that are principally practiced off-line (e.g. scratchcards, roulette, slot machines). Indeed, our sample is mainly constituted by individuals who gamble very few money by session (tables 1 and 2). We can presume that cognitive style and need for cognition might have a higher impact on bigger strategic and non-strategic gamblers. Second, the choice of the variables in our study was limited to characterize the sample. It would be interesting to include demographic and clinical variables in future studies (e.g. problem gambling, frequency of gambling or impulsivity). Third, the fact that strategic gamblers in our sample gambled more often than non-strategic gamblers could have influenced our results.

\section{Conclusion}

This study was the first to our knowledge to investigate participation in strategic and non-strategic games under the dual-process theories. Results have shown that gender, cognitive style and need for cognition predict gambling participation. Strategic gamblers were mainly males, more analytic, and showed a higher need for cognition than non-strategic gamblers. To our knowledge, this study is the first that effectively shows the analytic and motivational component of participation in strategic gamblers with both behavioral and self- 


\section{Running head: COGNITIVE CHARACTERISTICS}

reported data. We feel that it is important to continue research in this area to improve the efficacy of the prevention and treatment of excessive gambling.

\section{References}

Binde, P. (2013). Why people gamble: a model with five motivational dimensions. International Gambling Studies, 13(1), 81-97.

Bjerg, O. (2010). Problem gambling in poker: money, rationality and control in a skill-based social game. International Gambling Studies, 10(3), 239-254. https://doi.org/10.1080/14459795.2010.520330

Bonnaire, C., Bungener, C., \& Varescon, I. (2013). Alexithymia and gambling: A risk factor for all gamblers? Journal of Gambling Studies, 29(1), 83-96. https://doi.org/10.1007/s10899-012-9297-x

Boutin, C. (2010). Le jeu : chance ou stratégies? Choisir librement la place du jeu dans votre vie [The game: chance or strategies? Choose freely the place of the game in your life]. Montréal, Canada : Les éditions de l'homme.

Brañas-Garza, P., Kujal, P., \& Lenkei, B. (2015). Cognitive Reflection Test: Whom, how, when. Working paper. Accessed at the following Web address https://mpra.ub.unimuenchen.de/68049/

Cacioppo, J. T., \& Petty, R. E. (1982). The need for cognition. Journal of Personality and Social Psychology, 42(1), 116-131.

Cacioppo, J. T., Petty, R. E., \& Kao, C. F. (1984). The efficient assessment of need for cognition. Journal of Personality Assessment, 48(3), 306-307.

Chantal, Y., \& Vallerand, R. J. (1996). Skill versus luck: A motivational analysis of gambling involvement. Journal of Gambling Studies, 12(4), 407-418. 
Running head: COGNITIVE CHARACTERISTICS

Cueva, C., Iturbe-Ormaetxe, I., Mata-Pérez, E., Ponti, G., Sartarelli, M., Yu, H., \& Zhukova, V. (2016). Cognitive (ir)reflection: New experimental evidence. Journal of Behavioral and Experimental Economics, 64, 81-93. https://doi.org/10.1016/j.socec.2015.09.002

De Neys, W., \& Bonnefon, J.-F. (2013). The 'whys' and 'whens' of individual differences in thinking biases. Trends in Cognitive Sciences, 17(4), 172-178. https://doi.org/10.1016/j.tics.2013.02.001

Dickerson, M. (1993). Internal and external determinants of persistent gambling: Problems in generalising from one form of gambling to another. Journal of Gambling Studies, 9(3), $225-245$.

Evans, J. S. B. T., \& Stanovich, K. E. (2013). Dual-process theories of higher cognition: Advancing the debate. Perspectives on Psychological Science, 8(3), 223-241. https://doi.org/10.1177/1745691612460685

Frederick, S. (2005). Cognitive reflection and decision making. Journal of Economic Perspectives, 25-42.

Grant, J. E., Odlaug, B. L., Chamberlain, S. R., \& Schreiber, L. R. N. (2012). Neurocognitive dysfunction in strategic and non-strategic gamblers. Progress in NeuroPsychopharmacology \& Biological Psychiatry, 38(2), 336-340.

Haigh, M. (2016). Has the standard cognitive reflection test become a victim of its own success? Advances in Cognitive Psychology, 12(3), 145-149. https://doi.org/10.5709/acp-0193-5

Hoppe, E. I., \& Kusterer, D. J. (2011). Behavioral biases and cognitive reflection. Economics Letters, 110(2), 97-100. https://doi.org/10.1016/j.econlet.2010.11.015

Kahneman, D. (2011). Thinking, fast and slow. New York, NY: Farras, Straus and Giroux. LaPlante, D. A., Nelson, S. E., LaBrie, R. A., \& Shaffer, H. J. (2006). Men and women playing games: Gender and the gambling preferences of Iowa gambling treatment 
Running head: COGNITIVE CHARACTERISTICS

program participants. Journal of Gambling Studies, 22(1), 65-80.

https://doi.org/10.1007/s10899-005-9003-3

Lorains, F. K., Dowling, N. A., Enticott, P. G., Bradshaw, J. L., Trueblood, J. S., \& Stout, J. C. (2014). Strategic and non-strategic problem gamblers differ on decision-making under risk and ambiguity: Decision-making in problem gambling. Addiction, 109(7), 1128-1137. https://doi.org/10.1111/add.12494

Lorains, F. K., Stout, J. C., Bradshaw, J. L., Dowling, N. A., \& Enticott, P. G. (2014). Selfreported impulsivity and inhibitory control in problem gamblers. Journal of Clinical and Experimental Neuropsychology, 36(2), 144-157.

https://doi.org/10.1080/13803395.2013.873773

Moragas, L., Granero, R., Stinchfield, R., Fernández-Aranda, F., Fröberg, F., Aymamí, N., ... Jiménez-Murcia, S. (2015). Comparative analysis of distinct phenotypes in gambling disorder based on gambling preferences. BMC Psychiatry, 15(1). https://doi.org/10.1186/s12888-015-0459-0

Moreau, A., Chabrol, H., \& Chauchard, E. (2016). Psychopathology of online poker players: Review of literature. Journal of Behavioral Addictions, 5(2), 155-168. https://doi.org/10.1556/2006.5.2016.035

Odlaug, B. L., Marsh, P. J., Kim, S. W., \& Grant, J. E. (2011). Strategic vs nonstrategic gambling: Characteristics of pathological gamblers based on gambling preference. Annals of Clinical Psychiatry, 23(2), 105-112.

Petry, N. M. (2003). A comparison of treatment-seeking pathological gamblers based on preferred gambling activity. Addiction, 98(5), 645-655.

Priester, J. R., \& Petty, R. E. (1995). Source attributions and persuasion: Perceived honesty as a determinant of message scrutiny. Personality and Social Psychology Bulletin, 21(6), 637-654. https://doi.org/10.1177/0146167295216010 


\section{Running head: COGNITIVE CHARACTERISTICS}

Salama-Younes, M., Guingouain, G., Le Floch, V., \& Somat, A. (2014). Besoin de cognition, besoin d'évaluer, besoin de clôture : proposition d'échelles en langue française et approche socio-normative des besoins dits fondamentaux [Need for cognition, need for closing, need to evaluate: Proposal of scales in French and socio-normative approach of fundamental needs]. Revue Européenne de Psychologie Appliquée/European Review of Applied Psychology, 64(2), 63-75. https://doi.org/10.1016/j.erap.2014.01.001

Shi, X. (2013). Cognitive responses in advice planning: An examination of thought content and its impact on message features under high versus low effortful thinking modes. Journal of Language and Social Psychology, 32(3), 311-334.

Stevens, M., \& Young, M. (2010). Who plays what? Participation profiles in chance versus skill-based gambling. Journal of Gambling Studies, 26(1), 89-103. https://doi.org/10.1007/s10899-009-9143-y

Steward, W. T., Schneider, T. R., Pizarro, J., \& Salovey, P. (2003). Need for cognition moderates responses to framed smoking-cessation messages. Journal of Applied Social Psychology, 33(12), 2439-2464.

Stieger, S., \& Reips, U.-D. (2016). A limitation of the Cognitive Reflection Test: Familiarity. PeerJ, 4, e2395. https://doi.org/10.7717/peerj.2395

Toplak, M. E., West, R. F., \& Stanovich, K. E. (2014). Assessing miserly information processing: An expansion of the Cognitive Reflection Test. Thinking \& Reasoning, 20(2), 147-168. https://doi.org/10.1080/13546783.2013.844729

Wiers, R. W. H. J. \& Stacy, A. W. Implicit cognition and addiction: An introduction. In R. W. H. J., Wiers, \& A. W. Stacy, (Eds.) (2006). Handbook of implicit cognition and addiction (pp. 1-8). Thousand Oaks, CA: Sage. 
Running head: COGNITIVE CHARACTERISTICS

Young, M., \& Stevens, M. (2009). Player preferences and social harm: An analysis of the relationships between player characteristics, gambling modes, and problem gambling. International Journal of Mental Health and Addiction, 7(1), 262-279. https://doi.org/10.1007/s11469-008-9185-X

\section{Compliance with Ethical Standards}

\section{Conflict of interest}

There was no conflict of interest in conducting this study.

\section{The funding sources}

AM received a grant from the French Interdepartmental Mission for the Fight against Addictive Behaviors (MILDECA) and the School of Advanced Studies in Social Sciences (EHESS). VLF received funding from the "Jeu et Sociétés" group (Universities Paris Descartes, Paris Ouest Nanterre La Défense and Paris 13-SPC and the gambling industry operator FDJ) for other studies. GCB received several grants to support research programs: French Public Health Research Institute (IReSP) and its partners (call for tenders "Primary Prevention 2013"), French National Institution for Prevention and Health Education (INPES, research subvention), French Health Ministry (PHRC 2012 - 12-020-0177), University Hospital of Nantes (AOI 2013) and "Jeu et Sociétés" group (2015-2016). Those grants were part of other research contracts and had no influence on the present work. GCB also declares that the Federative Institute of Behavioral Addictions has received funding from the University Hospital of Nantes and gambling industry operators (FDJ and PMU). Scientific independence towards gambling industry operators is warranted. A. Moreau received funding from gambling industry operator Paris Mutuel Urbain (PMU). CJ received a scholarship from the Groupe de recherche sur l'intervention et les fondements en jeu (GRIF-Jeu). IG was 
Running head: COGNITIVE CHARACTERISTICS

financed for other studies on gambling by Fonds de recherche du Québec - Société et culture and received an infrastructure grant for GRIF-Jeu by Fonds de recherche du Québec - Société et culture.

\section{Role of Funding Sources}

Sponsors had no role in the study design, collection, analysis or interpretation of the data, writing the manuscript, or the decision to submit the paper for publication.

\section{Ethical approval}

All procedures performed in studies involving human participants were in accordance with the 1964 Helsinki declaration and its later amendments or comparable ethical standards.

\section{Informed consent}

All participants were informed of the confidentiality and the anonymity of their responses, and gave their free and informed consent. 